\title{
Global healthy backpack initiatives
}

\author{
Kapila Jayaratne $\mathrm{e}^{\mathrm{a},}$, Karen Jacobs ${ }^{\mathrm{b}^{*}}$ and Dulitha Fernando ${ }^{\mathrm{c}}$ \\ ${ }^{a}$ Maternal and Child Morbidity and Mortality Surveillance Unit, Family Health Bureau, Ministry of Health, 231 \\ De Saram Place Colombo 10, Sri Lanka \\ ${ }^{\mathrm{b}}$ Boston University, College of Health and Rehabilitation Sciences: Sargent College, Department of Occupational \\ Therapy, 635 Commonwealth Ave. Boston, MA 02215, USA \\ ${ }^{\mathrm{c}}$ Department of Community Medicine, Faculty of Medicine, University of Colombo, Sri Lanka.
}

\begin{abstract}
Schoolbag use by children is a global common concern.. Children carry school books and other amenities in their school bags. Global evidence indicates that daily load carried by school children may have negative health implications. Backpack as a school bag model, is the healthiest way of load carriage for school children. Several initiatives have been launched world over to minimize unhealthy consequences resulting from schoolbags. Based on a situation analysis, Sri Lanka implemented a national healthy schoolbag campaign by joint efforts of Ministries of Health and Education. Actions were contemplated on; strategies for bag weight reduction, introduction of an ergonomically modeled schoolbag and bag behaviour change. New strategies were introduced with awareness campaigns to policy makers, bag manufacturers, parents, teachers and children. Four million schoolchildren benefitted. In 2000, the backpack strategy of "Pack it Light, Wear it Right" was started as a public health initiative in the United States by the American Occupational Therapy Association (AOTA). Over the last eleven years, thousands of occupational therapy practitioners and students participated in educational programs and outreach activities. In 2004, modeled after the success AOTA initiative, the Icelandic Occupational Therapy Association launched a national backpack awareness initiative. This article shares examples of practices that could be implemented in any context to the promote health of children.
\end{abstract}

Keywords: schoolbag, ergonomic, occupational therapy, Sri Lanka, United States

\footnotetext{
*Corresponding authors. E-mail: kapjay613@gmail.com, kjacobs@bu.edu
} 


\section{Introduction}

Globally, schoolbags use by children is a common concern. Children carry a load of school books and other amenities in their school bags daily. Many research studies have reported that the daily load carried by school children may cause musculoskeletal pain (Negrini et al. 1999; Harreby et al. 1999; Szpalski et al. 2002; Viry et al. 1999). The weight of the school bag is often greater than the load recommended for children by the International Chiropractor Pediatric Association (ICPA) and the American Occupational Therapy Association (AOTA), 10\% of body weight (Chia and Wong 2002, AOTA, 2011).

\section{National Healthy Schoolbag Campaign of Sri Lanka}

Getting evidence-based research into practice proceeds from awareness through acceptance to adoption. Many scientific research findings are not translated into practice due to various factors. Unhealthy schoolbags were a concern to both health and education authorities in Sri Lanka. The growing interest over schoolbags of all the stakeholders of health of children catalyzed the exploration of strategies to mitigate the problem.

This project aimed to utilize outcomes of a health sector research on schoolbags into action by joint efforts with Ministry of Education

A situation analysis on carriage of schoolbag and negative health outcomes was done as a descriptive cross-sectional study in a representative district of Sri Lanka. A sample 1607 school children was included for the study using stratified multistage cluster sampling method from a total of 81,067 children in Grades 6, 7 and 8 in 407 schools in the selected district.

Research found that school children use different bag models; backpacks (79.6\%), shoulder bags $(17.9 \%)$, suitcase $(2.3 \%)$ and hand carriage $(0.1 \%)$ to carry their books and amenities. Mean carrying distance of the bag was $3.87 \mathrm{Km}(\mathrm{SD}=4.68)$. Mean carrying time of the bag was 24.07 minutes (SD = 15.79). Most (96.9\%) students always carried their school bag by themselves. Total weight of the bag was measured with all the contents inside. Such contents were classified in to three categories; text books $($ mean $=1.36 \mathrm{Kg})$, other books $($ mean $=1.13 \mathrm{Kg})$ and
Backpack as a school bag model, is the healthiest way of load carriage (Goodgold 2005) for school children causing minimal physiological distress (Malhotra and Sengupta 1965). Several initiatives have been launched world over to minimize negative consequences resulting from unhealthy schoolbags. This paper presents two exemplary backpack initiatives implemented in an industrially developed country (USA) and in a developing country (Sri Lanka) to emphasize that such good practices could be implemented in any contexts to promote the health of children.

non-book items $($ mean $=0.66 \mathrm{Kg})$. The mean weight of the school bag was $3.72 \mathrm{Kg}(\mathrm{SD}=1.05$, min 0.45 $\mathrm{Kg}$, max. $8.30 \mathrm{Kg}$ ). Text books accounted for an average of $36.56 \%$ of the total weight of the bag and other books and non-book items were $30.38 \%$ and $17.74 \%$ respectively.

Since a majority of children carried backpacks, several features related to backpack carriage were studied. A majority (97.1\%) of the students carried the backpack on both shoulders and only $2.9 \%$ carried the backpack in other styles (over one shoulder or backpack carried on hand). Of the backpacks observed $(\mathrm{N}=1279), 99.4 \%$ had movable straps, 91.6\% had padded shoulder straps and only $10.4 \%$ backpacks were compartmentalized. A waist-belt was present in $9.5 \%$ and of them only $30.5 \%$ students used the waist-belt.

The weight of the school bag as a percentage of the total body weight was $11.04 \%(\mathrm{SD}=3.88)$. A proportion of $57.9 \%$ students carried a bag heavier than $10 \%$ of their body weight. About $14 \%$ of the students carried a school bag weighing more than $15 \%$ of the body weight.
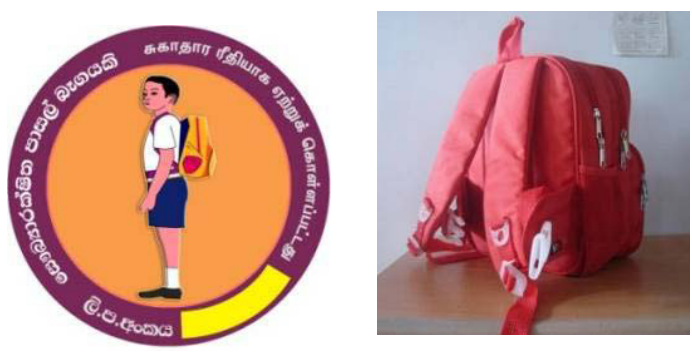

Fig. 1 - Healthy Schoolbag and Logo issued to Bag Manufacturers registered with Ministry of Education and complying with ergonomic standards 


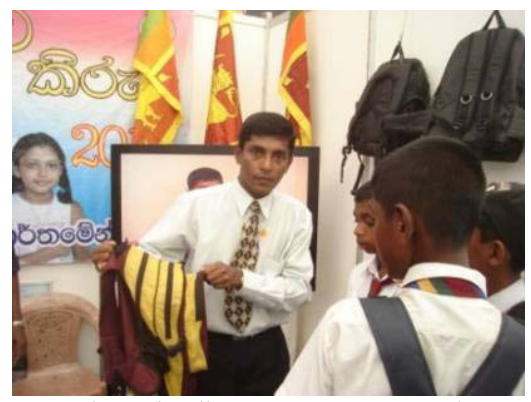

Fig. 2 Community Schoolbag Awareness campaigns conducted by Dr. Kapila Jayaratne, National Co-ordinator of Schoolbag campaign

Many children reported negative health consequences. A proportion of $71.8 \%$ perceived discomfort due to carriage of schoolbag. One third of children reported recurrent musculoskeletal pain. A larger proportion felt tired at the end of school sessions. Healthy bag behaviour resulted in lowering such risk.

These findings necessitated formulation of feasible solutions with the involvement of major stakeholders. Research outcomes were disseminated through mass media to general public. Outcomes were shared at international forums to obtain further inputs and update good practice evidence. Solutions were contemplated on; strategies for bag weight reduction, introduction of a model healthy bag and bag behaviour change. Findings and recommended solutions were shared with Ministry of Education which initiated a secondary research to find solutions to heavy schoolbag. Text books were split into several volumes. Only page- 80 exercise books were recommended. A healthy schoolbag with ergonomic features was modeled to suit Sri Lankan contexts. Bag manufacturers were registered and educated on design of model healthy bag. Children, Parents and teachers were educated through mass media, leaflets and at exhibitions. A schoolbag regulatory committee was set up. Advocacy of policy makers, especially ministers concerned, played a crucial role. Sri Lanka standards on schoolbags were formulated by a working committee consisted of Paediatricians, Public Health Specialists, Education administrators, Standard Engineers, Ergonomists, Textile Engineers and Bag manufacturers.

A pioneer health sector research led to uplift the health of nearly four million schoolchildren in Sri Lanka. This will be a model research work for prospective researchers.

\section{3. "Pack it Light, Wear it Right" public health backpack initiative in the United States}

In 2011, the American Occupational Therapy Association's (AOTA's) National School Backpack Awareness Day campaign celebrated its 11th anniversary (Jacobs, et al, 2010). For over eleven years, thousands of occupational therapy practitioners and occupational therapy students have participated in educational programs and outreach activities with the "Pack it Light, Wear it Right" public health initiative in the United States (See Figures 3 \& 4).

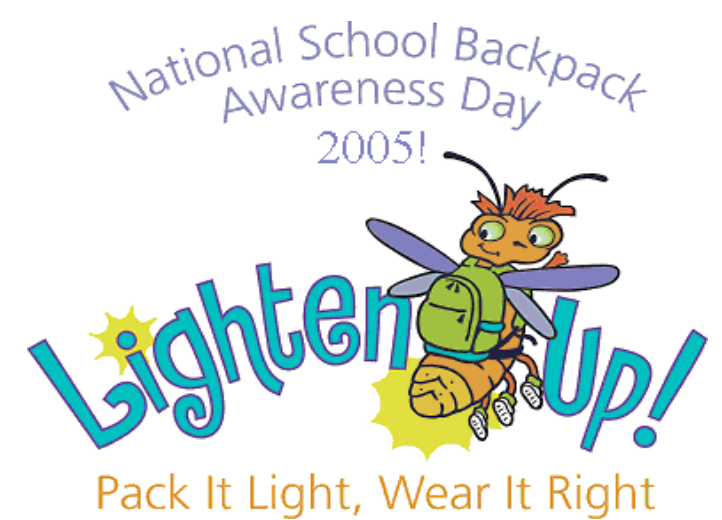

Fig. 3 The $\log 0$ of a lighting bug to reinforce the concept of "pack it light" was used from 2000-2009.

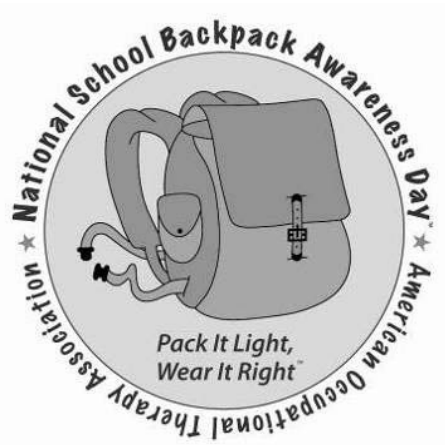

Fig. 4. In 2010, the American Occupational Therapy Association's logo for National School Backpack Awareness Day changed to a backpack because the initiative expanded the target audience to include persons across the lifespan (Jacobs, et al 2011)

The AOTA initiative includes the message for how to select the right backpack, how to pack it right and how to wear it correctly. Most backpack awareness day events have taken place in elementary and middle schools. Well-received approaches typically include a skit to engage the students (See Figure 5), 
weigh-in activity (See Figure 6), and adjusting backpacks.

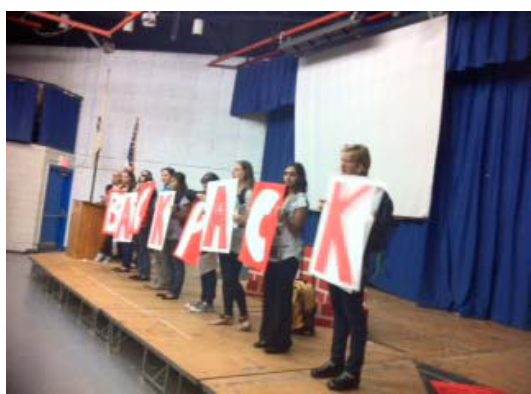

Fig. 5 Boston University occupational therapy students performing a backpack awareness skit at a local Boston Public School.

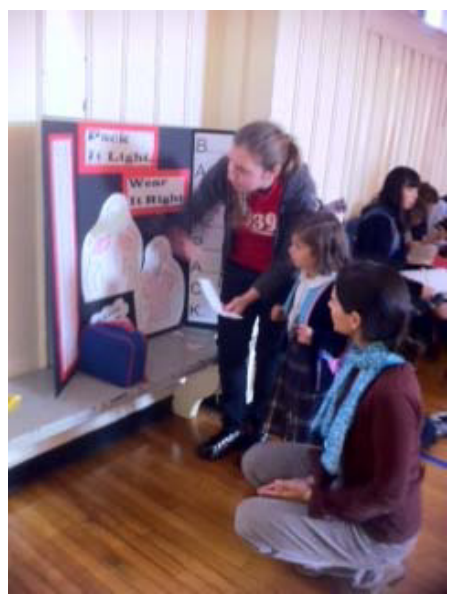

Fig. 6 Boston University occupational therapy working with an elementary student during a backpack weigh-in.

In 2005, over 300 Backpack Awareness events were held, reaching 10,000 children and millions more through TV and newspaper coverage (www.aota.org). In 2006, nearly 500 backpack events were held in schools, community centers, and retail facilities reaching more than 100,000 students in every state (www.aota.org). These figures continue to increase.

Modeled after AOTA's successful National Backpack Awareness Day, in 2005 occupational therapists and students created Backpack Awareness Days in Iceland. To ensure that the event was culturally relevant, a mascot of an elf was created and all materials were translated into Icelandic.

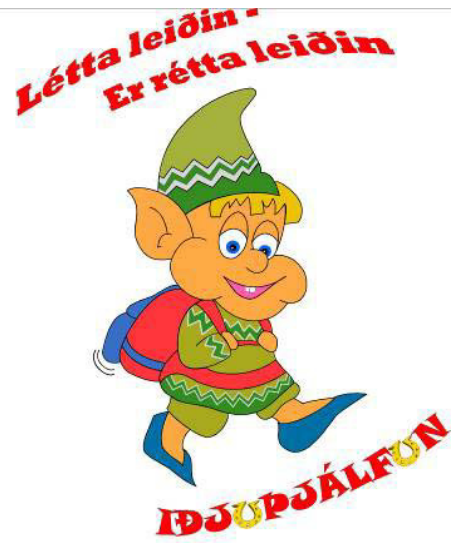

Fig 7. Mascot used for the National School Backpack Awareness initiative in Iceland. The words on the top say "Pack it Light, Wear it Right" and on the bottom say occupational therapy in Icelandic.

In 2006, the first year of this Icelandic public health initiative, 54 schools and over 1965 students ( $\sim 5 \%$ of all students in Iceland) participated in Backpack Awareness Days. Thirty two occupational therapists and many students hosted the days events. This event continues each year.

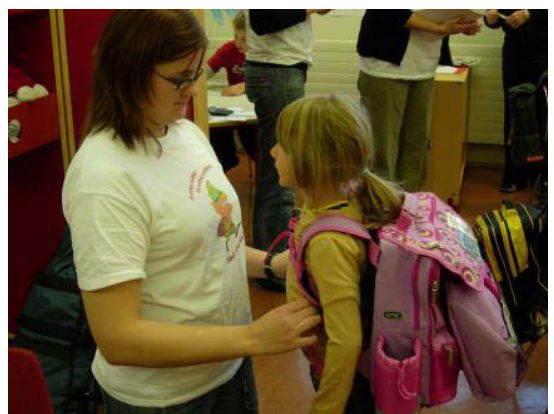

Fig 8. Backpack weigh-in at a public school in Iceland.

\section{Conclusion}

Schoolbag use by children is a global common concern. This paper described success initiatives to promote healthy backpack use which could be mplemented in any context to the promote health of children.

\section{References}

[1] Chia, M. \& Wong, J. (2002). Small backs need minding. ACHPER Australian Healthy Lifestyles Journal, 49(3-4), 14 $18 \& 25$.

[2] American Occupational Therapy Association (2011) www.aota.org 
[3] Goodgold SA, (2005). Backpack Intelligence: Implementation of a Backpack Safety Program with Fifth Grade Students. Orthopaedic Practice Vol. 15;3:03

[4] Malhotra M and Sengupta J (1965), Carrying of schoolbags by children, Ergonomics, 8, 1, pp 55-60

[5] Negrini S, Carabalona R, Sibila P. (1999).Backpack as a daily load for schoolchildren. Lancet;354:1974.

[6] Szpalski M, Gunzburg R, Balagué F, Nordin M, Mélot C. (2002). A 2-year prospective longitudinal study on low back pain in primary school children. European Spine Journal 11: 459-464.
[7] Viry P, Creveuil C, Marcelli C. (1999). Nonspecific back pain in children: a search for associated factors in 14 year old schoolchildren. Rev Rhum Engl Ed ;66:381-8.

[8] Jacobs, K., Sanders, M., Dapito, D., Flores, A., Hellman, M., Markowitz, J., Wuest, E., Wilkeson, E., Bencivenga, M., Berger, V., Doherty, K., Rohan, B., Stafford, K., Trownbridge, N. (July 26, 2010). Backpack Awareness Across the Lifespan. OT Practice.

[9] Jacobs, K., Wuest, E., Markowitz, J., Hellman, H. (July 25, 2011). Get Packing, OT Practice 